\title{
Abnormal Expression of Long Noncoding RNAs in Primary Immune Thrombocytopenia: A Microarray Related Study
}

\author{
Tengda Lia Mingli Gub Peng Liu ${ }^{\mathrm{a}} \quad$ Yun Liu ${ }^{\mathrm{b}} \quad$ Jie Guo ${ }^{\mathrm{b}} \quad$ Weiwei Zhang ${ }^{\mathrm{b}}$ \\ Anmei Deng ${ }^{\mathrm{a}, \mathrm{c}, \mathrm{d}} \quad$ Cheng Qian ${ }^{\mathrm{e}}$ \\ aCenter of Clinical Experiments, Changhai Hospital, Second Military Medical University, \\ Shanghai, ${ }^{b}$ Department of Laboratory Diagnosis, Changhai Hospital, Second Military Medical University, \\ Shanghai, 'North Sichuan Medical College, Sichuan, dShanxi University of Chinese Medicine, Xianyang, \\ eThe 100th Hospital of PLA, Suzhou, China
}

\section{Key Words}

Long noncoding RNA - Primary immune thrombocytopenia - Microarray $\cdot$ Quantitative realtime polymerase chain reaction $\cdot$ Co-expression network construction.

\begin{abstract}
Background/Aims: Long noncoding RNAs (IncRNAs) are important regulators of biological processes and they contribute to the pathological developments of various diseases, including autoimmune diseases. To gain the further understanding, we estimate the expression of IncRNAs in primary immune thrombocytopenia (ITP). Methods: In this study, microarray studies were performed to characterize expression profiles of various IncRNAs and mRNAs in blood samples collected from ITP patients. Quantitative real-time PCR (qRT-PCR) was performed to confirm the results, Kyoto Encyclopedia of Genes and Genomes (KEGG) analysis and gene ontology analysis were used to provide functional annotations, co-expression network construction (CNC) analysis was made to reveal the relations between IncRNAs and their targeted genes. Results: A total of 1177 and 632 IncRNAs were significantly up-regulated or down-regulated, respectively, in "newly diagnosed ITP" patients versus healthy individuals. In addition, 1182 genes and 737 genes were up-regulated or down-regulated, respectively, in "chronic recurrent ITP" patients versus healthy individuals. In a KEGG analysis, "TNF signaling pathway-Homo sapiens (human)" was a key result. In a gene ontology analysis, "Granulocyte macrophage colony-stimulating factor production (GO:0032604, ontology: Biological process, $\mathrm{P}=1.69577 \mathrm{E}-05)$ " and "coreceptor activity (GO: 0015026, ontology: molecular function, $\mathrm{P}=$ 4.67594E-06)" were the two most critical results. Data from qRT-PCR and receiver operating characteristic curves further demonstrated that ENST00000440492, ENST00000528366,
\end{abstract}

T. Li and M. Gu contributed equally to this work.

\begin{tabular}{ll}
\hline Cheng Qian & The 100th Hospital of PLA, Suzhou 215007 (China) \\
and Anmei Deng & and Changhai Hospital, Shanghai 200433(China) \\
& E-Mail qiancheng824@163.com, amdeng70@163.com
\end{tabular}

\section{KARGER}




\section{Cellular Physiology Cell Physiol Biochem 2018;48:618-632 \begin{tabular}{c|c|c|c|} 
DOI: 10.1159/000491890 & $\begin{array}{l}\text { O 2018 The Author(s). Published by S. Karger AG, Basel } \\
\text { www.karger.com/cpb }\end{array}$
\end{tabular} \\ Li et al.: Abnormal Long Noncoding RNAs in Primary Immune Thrombocytopenia}

NR_038920, and ENST00000552576 can efficiently distinguish different stages of ITP, especially NR_038920 and ENST00000528366. In a CNC analysis, four IncRNAs were emphasized, and NR_038920 and ENST00000528366 were both associated with proteins with important roles in autoimmune diseases. Conclusions: These results suggest that IncRNAs act through targeted genes to mediate their functions and to mediate their functions and affect the pathogenesis of ITP.

(C) 2018 The Author(s)

Published by S. Karger AG, Basel

\section{Introduction}

Primary immune thrombocytopenia (ITP), also known as idiopathic thrombocytopenic purpura, is an autoimmune disorder characterized by a decrease in platelets due to autoantibody-mediated destruction of platelets or compromised platelet production [1, 2]. It has been reported that pathological autoantibodies produced by B cells, aberrant $\mathrm{T}$ lymphocytes, and especially the turbulent developed megakaryocytes, significantly contribute to ITP[3-6]. Previous studies have demonstrated that most immune disorders are caused by dysregulation of gene expression [7,8], and changes in phenotypes are often manifestations of changes in gene regulation [9-11]. In addition to coding genes, noncoding genes such as microRNAs and IncRNAs have increasingly gained attention [12-14]. LncRNAs have recently been discovered to be noncoding RNAs with lengths greater than 200 nucleotides [15]. Based on proximal protein-coding mRNAs, lncRNAs have been classified as sense lncRNAs, antisense lncRNAs, intronic lncRNAs, bidirectional lncRNAs, and long intergenic ncRNAs (lincRNAs). LncRNAs have been shown to affect every stage of a gene's life cycle, including chromosome reconstruction, transcription, post-transcription, and intracellular metabolism [15-18]. In a recent study, the role of lncRNAs in the development of autoimmune diseases was highlighted [19]. For example, the lncRNAs, Gas5, Hotair and H19, and Tmevg1, have roles in systemic lupus erythematosus (SLE) [20, 21], rheumatoid arthritis (RA) [22, 23], and Sjögren syndrome (SS)[24], respectively. However, few studies have investigated IncRNAs in ITP. Among these studies, the lncRNA, TMEVPG1, has been shown to be related to Th1-type transcription factors, T-bet, STAT1, and STAT4, thereby indicating the importance of IncRNAs in the pathology of ITP[25]. In the present study, a microarray analysis of IncRNAs and mRNAs in blood samples collected from newly diagnosed ITP patients $(n=3)$, chronic recurrent ITP patients ( $\mathrm{n}=3)$, and healthy individuals $(\mathrm{n}=3)$ was conducted (Fig. 1). The goal was to identify differentially expressed IncRNAs which may participate in the development of ITP. In addition, quantitative real-time PCR (qRT-PCR) was performed to detect selected lncRNAs in a larger number of patient samples, and bioinformatics methods were applied to reveal potential functions.

\section{Materials and Methods}

\section{Patient selection}

All of the subjects enrolled in this study received treatment at No. 100 Hospital of PLA (Suzhou, Jiangsu, China) or Changhai Hospital (Shanghai, China) between October 2014 and January 2015. There were

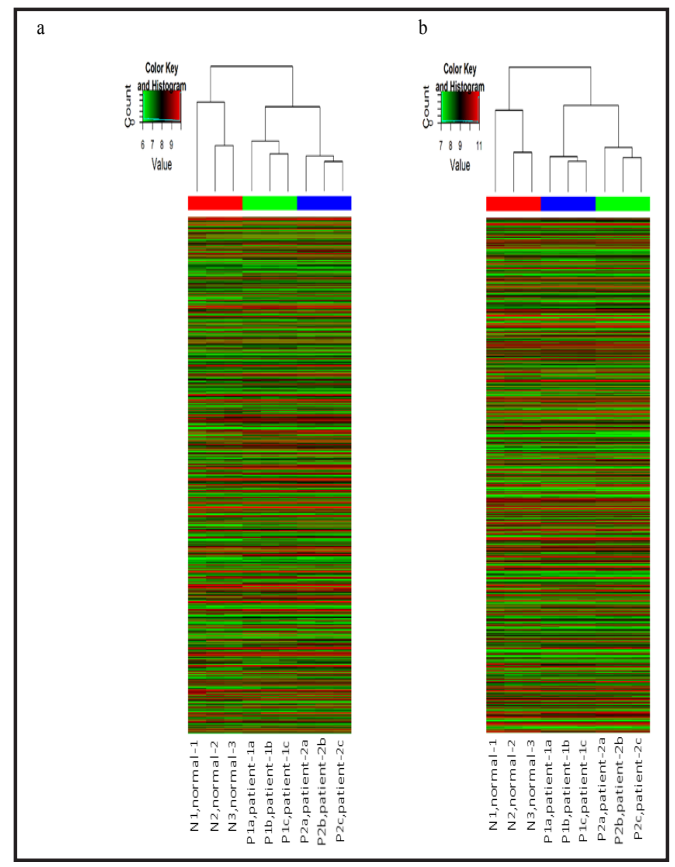

Fig. 1. Hierarchical clustering for $\operatorname{lncRNAs(a)}$ and mRNAs(b) detected in healthy individuals(N1-3), newly diagnosed ITP cases(P1a-c), and chronic recurrent ITP patients(P2a-c). 


\section{Cellular Physiology Cell Physiol Biochem 2018;48:618-632 \begin{tabular}{c|c|c|} 
DOI: 10.1159/000491890 & $\begin{array}{l}\text { O 2018 The Author(s). Published by S. Karger AG, Basel } \\
\text { www.karger.com/cpb }\end{array}$
\end{tabular} \\ Li et al.: Abnormal Long Noncoding RNAs in Primary Immune Thrombocytopenia}

no statistically significant differences among the patients in regard to gender or age. Patients referred to as having "newly diagnosed ITP" (termed P1 below) included diagnosed patients without reliable predictive clinical or laboratory parameters of disease duration. The patients referred to as having "chronic recurrent ITP" (termed P2 below) were previously diagnosed with ITP that persisted for more than 12 months, as previously detailed [26]. Healthy individuals composed the $\mathrm{N}$ group and they were examined for the same period of time as the $\mathrm{P} 1$ and $\mathrm{P} 2$ patients. Table 1 summarizes the characteristics of the P1 $(n=30)$ and P2 $(n=30)$ patients. Pregnant patients and those with diabetic complications, cardiovascular disease, an active infection, hypertension, or other autoimmune diseases were excluded. The Ethics Committee of the People's Liberation Army 100th Hospital and Changhai Hospital approved this research. The procedures performed were carefully explained to the patients and informed consents were signed by all of the participating patients. All experiments in the methods section were performed in accordance with approved international guidelines and ethical standards.
Table 1. Characteristics of the patients with ITP. Abbreviations: ITP: immune thrombocytopenia; PLT: platelet; IVIG: intravenous immunoglobulin; GP: glycoprotein; GC: glucocorticoid; P1: newly diagnosed ITP; P2: chronic ITP

\begin{tabular}{lcc}
\hline Variables & P1 No. patients(\%) & P2 No. patients(\%) \\
\hline Age of the ITP patients (y) & & \\
$\quad \leq 20$ & $4(13.3 \%)$ & $2(6.7 \%)$ \\
$20-40$ & $10(33.3 \%)$ & $14(46.7 \%)$ \\
$40-60$ & $8(26.7 \%)$ & $12(40.0 \%)$ \\
$\geq 60$ & $8(26.7 \%)$ & $2(6.7 \%)$ \\
Male & $4(13.3 \%)$ & $16(53.3 \%)$ \\
Course(mo) & & \\
$\leq 1(P 1) 3-100(P 2)$ & $26(86.7 \%)$ & $22(73.3 \%)$ \\
1-3(P1) 100(P2) & $4(13.3 \%)$ & $8(26.7 \%)$ \\
PLT count $\leq 10 \times 10 \% / L$ & $12(40.0 \%)$ & $18(60.0 \%)$ \\
Anti-platelet antibodies & & \\
GPIIb+ & $12(40.0 \%)$ & $16(53.3 \%)$ \\
GPIIIa+ & $18(60.0 \%)$ & $14(46.7 \%)$ \\
GPIb/IX+ & $14(46.7 \%)$ & $8(26.7 \%)$ \\
GPIb+ & $14(46.7 \%)$ & $16(53.3 \%)$ \\
Therapy & & \\
GC & $4(13.3 \%)$ & $30(100.0 \%)$ \\
IVIG & $2(6.7 \%)$ & $16(53.3 \%)$ \\
\hline
\end{tabular}

\section{Patient specimens}

Peripheral blood ( $6 \mathrm{~mL}$ ) was collected from each subject. To isolate peripheral blood mononuclear cells (PBMCs), the collected blood samples were diluted with PBS (pH 7.2-7.4, Jiru Biology Company, Shanghai, China) and then slowly added to Ficoll-Hypaque (Thermo Fisher Scientific, USA). After centrifugation at $2500 \mathrm{rpm}$ for $20 \mathrm{~min}$, the obtained PBMCs were washed twice with PBS, were added into $1 \mathrm{ml}$ Trizol reagent (Invitrogen, USA) and then were stored at $-80^{\circ} \mathrm{C}$

\section{RNA isolation}

Prepared blood samples were thawed at room temperature (RT) before chloroform was added to each sample. After a brief vortexing step, the samples were centrifuged $\left(12000 \times \mathrm{g}, 5 \mathrm{~min}, 4{ }^{\circ} \mathrm{C}\right)$ and the supernatants were transferred to RNase-free eppendorf tubes and mixed with isopropyl alcohol. After an incubation at RT for $30 \mathrm{~min}$ and another centrifugation step $\left(12000 \times \mathrm{g}, 15 \mathrm{~min}, 4^{\circ} \mathrm{C}\right)$, the supernatants were precipitated with cold $75 \%$ alcohol and centrifuged $\left(12000 \times \mathrm{g}, 5 \mathrm{~min}, 4{ }^{\circ} \mathrm{C}\right)$. The pellets were dried at RT for 2-5 min and then $20 \mathrm{ul}$ of RNase-free water was added to each. From each sample, a 1 ul aliquot was analyzed for RNA concentration and purity with a Nanodrop 2000 instrument (Thermo Scientific, USA).

\section{Microarray to obtain expression profiles for IncRNAs and mRNAs}

An Arraystar Human LncRNA Microarray V3.0 (Arraystar Inc., USA) was used based on its capacity to evaluate 30, 586 lncRNAs and 26, 109 coding transcripts. To prepare samples for analysis, total RNA was isolated as described above. Both RNA integrity and genomic DNA contamination were assayed by denaturing agarose gel electrophoresis performed with an Agilent Bioanalyzer 2100 instrument (Agilent Technologies, USA) by KangChen (Shanghai, China). Total RNA was purified with RNeasy Mini Kits (Qiagen, Germany) and Baseline-ZERO DNase (EPICENTRE, USA) according to the manufacturers' protocols. A One-Color Quick Amp Labeling Kit (Agilent, USA) was used to label samples. The labeled samples were subsequently purified, along with labeled cRNA as a quality control, with RNeasy Mini Kits (Qiagen, Germany) according to the manufacturer's protocol. Specific activity (pmol dye per g cRNA) was calculated as follows: specific activity $=(\mathrm{pmol}$ per ul dye $) /($ ug per ul cRNA $)$. Array hybridization was performed according to the manufacturer's protocol for the Agilent Gene Expression Hybridization Kit (Agilent, USA). The hybridized 


\section{Cellular Physiology Cell Physiol Biochem 2018;48:618-632

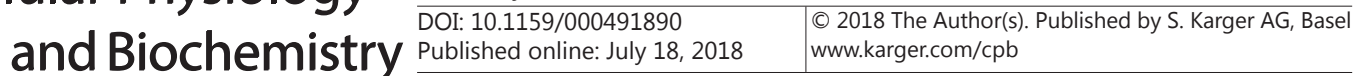

Li et al.: Abnormal Long Noncoding RNAs in Primary Immune Thrombocytopenia

array was washed with Gene Expression Wash Buffer 1 and Gene Expression Wash Buffer 2 (Agilent, USA) before being scanned by an Agilent Microarray Scanner. Data were subsequently extracted and analyzed with Agilent Feature Extraction Software (V11.0.1.1).

\section{Data analysis}

Raw data were imported into GeneSpring GXv12.1 software (Agilent, USA) for quantile standardization. Differentially expressed LncRNAs and mRNAs with statistically significant differences between each set of comparisons were identified with P-value/ false discovery rate filtering. For the differently expressed IncRNAs or mRNAs, we selected them according to the following standards: 1 ) the fold change was $\geqslant 2.0$ and P-value $\leqslant 0.05 ; 2$ ) the raw intensity was $\geqslant 200$ to make the background intensity as small as possible; 3 ) the Xhyb column was blank to make sure that there was not non-specific detection. Hierarchical clustering and combined analysis were performed with homemade scripts. To better understand the functions of the identified IncRNAs, correlations between enhancer IncRNAs, antisense IncRNAs, lincRNAs, and nearby mRNAs were analyzed. A gene ontology (GO) analysis was performed and the categories included: Molecular Function (MF), Biological Process (BP), and Cellular Component (CC). P-values were obtained according to Fisher's exact test and were used to measure GO term enrichment for differentially expressed IncRNAs and mRNAs. To calculate fold enrichment of a GO term, the number of differentially expressed genes and those with an assigned GO term ("Count"), the number of genes annotated in the database ("Pop.Nits"), the number of different genes with GO annotations ("List.Total"), and the total number of genes in the database (background) with a GO annotation ("Pop.Total"), were used as follows: (Count / Pop.Nits) / (List.Total / Pop.Total), Enrichment Score = -log(P-value). A Kyoto Encyclopedia of Genes and Genomes (KEGG) Pathway analysis showed every gene/protein or small molecule in each Pathway Map it generated. Histograms presented the enrichment scores of the pathway terms. A Volcano plot was used to select differentially expressed mRNAs and lncRNAs (for all online suppl. material, see www.karger.com/ doi/10.1159/000491890, Fig. S3a-c). A scatter plot was generated to present repeatability among the microarray data and groups (see online suppl. material, Fig. S3d-f). Probe distribution in the microarray is presented in a box plot, with changes before and after standardization shown (see online suppl. material, Fig. S3g-h). To display similar biological properties in multiple samples, hierarchical clustering was performed with Aligent GeneSpring GX software (version 11.5.1) (Fig. 1).

Fig. 2. CNC analysis results for 12 IncRNAs (a) and a subset of 4 immune-related IncRNAs [ENST00000528366, and ENST00000440492, NR_038920, and ENST00000552576] and their related genes (b). (a) The bluegreen nodes represent coding genes, the red nodes represent lncRNAs. Solid lines indicate positive relationships between the IncRNAs and coding genes, and the dotted lines indicate negative relationships. (b) In this second CNC network, there were 47 nodes representing mRNAs, as well as related genes. The related genes were presented in colors that indicate their level of significance in immunity or autoimmunity (significance: blue-green > green > yellow-green $>$ yellow).

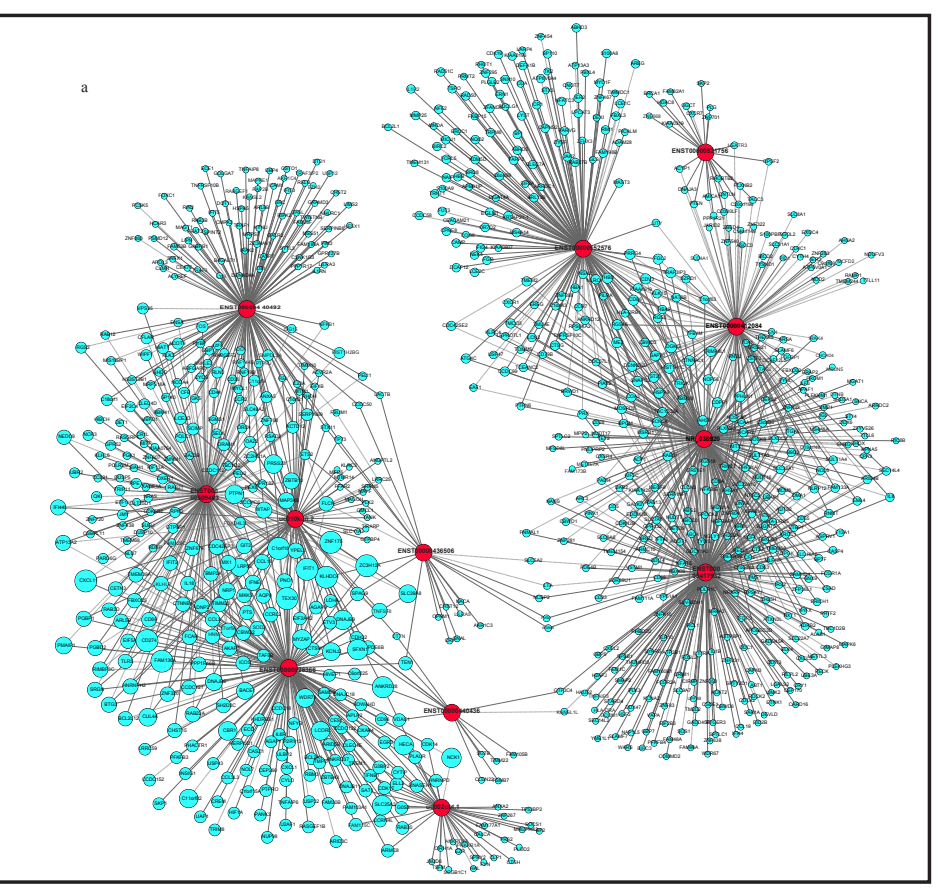




\section{Cellular Physiology Cell Physiol Biochem 2018;48:618-632 \begin{tabular}{ll|l} 
DOI: 10.1159/000491890 & $\begin{array}{l}\text { O 2018 The Author(s). Published by S. Karger AG, Basel } \\
\text { www.karger.com/cpb }\end{array}$
\end{tabular}

Synthesis of cDNA and qRT-PCR

For the synthesis of cDNA, an annealing mixture composed of $1.5 \mathrm{ug}$ RNA, 1 ul oligo(dT)18 ( $0.5 \mathrm{ug} / \mathrm{ul})$, 1.6 ul dNTPs mix ( $2.5 \mathrm{mM}$ ) (HyTest Ltd., China), and 10.4 ul RNA-free $\mathrm{H}_{2} \mathrm{O}$ was used. After the samples were incubated in the annealing mixture in a water bath at $65^{\circ} \mathrm{C}$ for $5 \mathrm{~min}$, and then in an ice bath for $2 \mathrm{~min}$, the samples were subjected to a short centrifugation. The following reagents were then added in this order: 4 ul 5X First-Strand Buffer (Invitrogen, USA), 1 ul 0.1M DTT, 0.3 ul RNase Inhibitor (Epicentre, USA), and 0.2 ul SuperScript III RT (Invitrogen, USA). The samples were incubated at $37^{\circ} \mathrm{C}$ for $1 \mathrm{~min}$, at $50^{\circ} \mathrm{C}$ for $60 \mathrm{~min}$, and then at $70^{\circ} \mathrm{C} 15 \mathrm{~min}$ in a thermostatic water tank (DK-8D, Senxin Instruments Inc., Shanghai, China). For immediate use, the samples were placed on ice, while samples were stored at $-20^{\circ} \mathrm{C}$ for later use.

PCR reactions were performed with 2X PCR Master Mix (Arraystar, USA) according to the manufacturer's protocol. See online suppl. material, Table S2 provides a list of the primers used. $\beta$-Actin was detected as a reference gene and relative quantification was performed to measure gene expression levels. PCR amplification was subsequently performed to verify selected genes from the IncRNA microarray analysis in 30 patients with "newly diagnosed ITP" (P1) and 30 patients with "chronic recurrent ITP" (P2) (Table 1). ROC curves and areas under the ROC curves (AUCs) for the qRT-PCR results of the selected genes were generated with GraphPad Prism 6.0 software (GraphPad, USA).

\section{Co-expression network construction}

Normalized intensities of coding genes were calculated to perform a co-expression network construction (CNC) analysis. When there were varying intensity values for different transcripts of the same gene, the median value of these intensities was used as the expressed value of the gene. The Pearson correlation coefficient (pcc) of the normalized intensities of the selected IncRNAs and all of their related genes was also calculated. When [abs(pcc)] was $>0.998$ and false discovery rate (FDR) was $<0.05$, the record was acquired. All of the records were plotted with Cytoscape (version 3.4.0) to construct a co-expression network that is shown in Fig. 2. Considering the immune functions demonstrated for the related genes in previous reports [27-42], 12 IncRNAs were selected for CNC analysis (Fig. 2a). Subsequently, the four most important IncRNAs (ENST00000440492, ENST00000528366, ENST00000552576, and NR_038920) and related genes according to their immunological function were selected for a CNC analysis (Fig. 2b).

\section{Results}

\section{Differentially expressed IncRNAs}

Compared with healthy controls (the N group), a total of 7878 lncRNAs were found to be up-regulated in newly diagnosed ITP patients (the P1 group), among which only 451 lncRNAs exhibited significant differences according to the standards as described above. The lncRNA that exhibited the greatest fold-change was NR_037166 (fold-change: 18.2). Meanwhile, a total of 7692 lncRNAs (312 of which exhibited significant differences) were down-regulated between the $\mathrm{P} 1$ and $\mathrm{N}$ groups. The most remarkable decrease in expression was exhibited by TCONS_00003870 (fold change: 93.6).

The total number of up-regulated lncRNAs between the chronic recurrent group (P2) and the N group was 9313 (with 376 lncRNAs exhibiting significant differences). The total number of down-regulated lncRNAs was 6257 (with 393 of these exhibiting significant differences) between the P2 and N groups. The most notably up-regulated lncRNA was TCONS_00000918 (fold-change: 13.9), while TCONS_00003870 (fold-change: 186.4) was the most down-regulated lncRNA.

Between the P2 and P1 groups, a total of 9392 up-regulated lncRNAs (with 100 exhibiting significant differences) and 6178 down-regulated lncRNAs (with 191 exhibiting significant differences) and their related genes were analyzed. The antisense lncRNAs that exhibited the greatest change between the P1 and N groups, between the P2 and N groups, and between the P2 and P1 groups were: uc010kun.2, NST00000559553, and ENST00000559553, respectively. Detailed information regarding these analysis is presented (see online suppl. material,) in Table S1 (a, b, and e). A hierarchical clustering analysis of lncRNAs detected in three healthy controls, three newly diagnosed ITP patients, and three chronic recurrent ITP 


\section{Cellular Physiology Cell Physiol Biochem 2018;48:618-632 \\ \begin{tabular}{ll|l} 
and Biochemistry Published onIIne: July 18, 2018 & $\begin{array}{l}\text { (c) } 2018 \text { The Author(s). Published by S. Karger AG, Basel } \\
\text { www.karger.com/cpb }\end{array}$ \\
\hline
\end{tabular}}

Li et al.: Abnormal Long Noncoding RNAs in Primary Immune Thrombocytopenia

patients is shown in Fig. 1a. We further analyzed the chromosomal derivation of the top10 lncRNAs in each group and found that in up-regulated groups (including P1 vs N, P2 vs N, P2 vs P1), those lncRNAs were focused on chr8 and chr11, while in down-regulated groups, they were mainly on chr2, chr12.

\section{Differentially expressed $m R N A s$}

An mRNA analysis of the P1 versus $\mathrm{N}$ samples, the P2 versus $\mathrm{N}$ samples, and the P2 versus P1samples identified 9519 up-regulated mRNAs (with 363 of these mRNAs exhibiting significant differences), 9795 up-regulated mRNAs (with 234 of these mRNAs exhibiting significant differences), and 9997 up-regulated mRNAs (with 40 of these mRNAs exhibiting significant differences), respectively. The most up-regulated mRNAs in each analysis were: NM_001008 (fold-change: 68.2), NM_001008 (fold-change: 84.0), and ENST00000361255 (fold-change: 5.4), respectively. Conversely, there were 10779 mRNAs that were downregulated in the $\mathrm{P} 1$ group versus the $\mathrm{N}$ group (with 353 of these mRNAs exhibiting significant differences), 10503 mRNAs down-regulated in the P2 versus N group (with 516 of these mRNAs exhibiting significant differences), and 10301 mRNAs down-regulated in the P2 versus P1 groups (with 183 of these mRNAs exhibiting significant differences). The mostdownregulated mRNAs in each group were: NM_002090 (fold-change: 48.4), NM_002090 (fold-change: 84.4), and NM_003246(fold-change: 8.4), respectively. Details of these analyses are summarized (see online suppl. material) in Table S1 (c,d).

\section{GO analysis}

A GO analysis of the P1 group versus the N group data showed that the greatest fold enrichment of GO terms for the up-regulated transcripts included: long-chain fatty acid binding (GO:0036041, ontology: MF, P = 0.000686924), response to bacterium (GO:0009617, ontology: BP, P = 9.31494E-09), and retromer complex (GO:0030904, ontology: CC, $\mathrm{P}=$ 0.000642907). The highest fold enrichment of GO terms for the down-regulated transcripts were: granulocyte macrophage colony-stimulating factor production (G0:0032604, ontology: $\mathrm{BP}, \mathrm{P}=1.69577 \mathrm{E}-05)$, coreceptor activity (GO:0015026, ontology: $\mathrm{MF}, \mathrm{P}=4.67594 \mathrm{E}-06$ ), and $\mathrm{T}$ cell receptor complex (GO:0042101, ontology: $\mathrm{CC}, \mathrm{P}=0.012832272$ ). Detailed information regarding these analyses are provided (see online suppl. material) in Fig. S1.

A GO analysis of the P2 group versus the N group data showed that the greatest fold enrichment of GO terms for the up-regulated transcripts included: oxygen transporter activity (GO:0005344, ontology: MF, P = 1.60566E-06), hemoglobin complex (GO:0005833, ontology: CC, $\mathrm{P}=3.78385 \mathrm{E}-07$ ), and oxygen transport (GO:0015671, ontology: $\mathrm{BP}, \mathrm{P}=$ 3.65271E-06). For the down-regulated transcripts, the greatest fold enrichment of GO terms included: mRNA cap binding complex (GO:0005845, ontology: CC, $\mathrm{P}=0.000243535$ ), fever generation (GO:0001660, ontology: $\mathrm{BP}, \mathrm{P}=0.000102935)$, and activin binding (G0:0048185, ontology: MF, $\mathrm{P}=0.003340754$ ).

Finally, a GO analysis of the P2 group versus the P1 group showed that the greatest fold enrichment of GO terms for the up-related transcripts included: hemoglobin complex (G0:0005833, ontology: CC, P = 9.60704E-10), oxygen transport (GO:0015671, ontology: $\mathrm{BP}, \mathrm{P}=6.65012 \mathrm{E}-07$ ), and oxygen transporter activity (G0:0005344, ontology: $\mathrm{MF}, \mathrm{P}=$ 4.09006E-07). For the most down-regulated transcripts, the most enriched GO terms were: extracellular region (G0:0005576, ontology: CC, P = 6.75631E-09), cGMP-mediated signaling (GO:0019934, ontology: BP, P = 7.52627E-05), and IgG binding (G0:0019864, ontology: MF, $\mathrm{P}=0.003234109$ ).

\section{Pathway analysis}

For up-regulated transcripts, the highest enrichment score pathways included: Legionellosis-Homo sapiens (human) (Fisher P-value $=2.51334 \mathrm{E}-05$ ) in the P1 versus $\mathrm{N}$ analysis, Legionellosis-Homo sapiens (human) (Fisher P-value $=0.001259538$ ) in the P2 versus $\mathrm{N}$ analysis, and Glycine, serine, and threonine metabolism - Homo sapiens (human) (Fisher P-value $=0.00173499$ ) in the P2 versus P1 analysis (see online suppl. material, Fig. 


\section{Cellular Physiology Cell Physiol Biochem 2018;48:618-632 \begin{tabular}{l|l} 
DOI: 10.1159/000491890 & $\begin{array}{l}\text { O } 2018 \text { The Author(s). Published by S. Karger AG, Basel } \\
\text { www.karger.com/cpb }\end{array}$
\end{tabular} \\ Li et al.: Abnormal Long Noncoding RNAs in Primary Immune Thrombocytopenia}

S2d-f). For the down-regulated transcripts, the most enriched pathways were: TNF signaling pathway - Homo sapiens (human) (Fisher P-value $=1.22301 \mathrm{E}-08$ ) in the P1 versus $\mathrm{N}$ analysis, NF-kappa B signaling pathway - Homo sapiens (human) (Fisher P-value $=5.63797 \mathrm{E}-08$ ) in the $\mathrm{P} 2$ versus $\mathrm{N}$ analysis, and Rheumatoid arthritis - Homo sapiens (human) (Fisher P-value $=9.70212 \mathrm{E}-06$ ) in the P2 versus P1 analysis (see online suppl. material, Fig. S2a-c). The two most common pathways were the "NF APPA signaling pathway" and the "TNF signaling pathway" (see online suppl. material, Fig. S2, g and h).

\section{CNC analysis}

A total of 12 lncRNAs were selected from among the differentially expressed lncRNAs for CNC analysis. There were also nodes representing mRNAs related to the lncRNAs (a total of 912 different mRNAs) that were analyzed (Fig. 2a). Many of the mRNAs in the network were shared by two or more IncRNAs, yet the relationships were distinct. For example, CXCL11 was positively related to ENST00000528366 and uc010kun.2 (both connected by a solid line), yet was negatively related to ENST00000509463 (connected by a dotted line). Similarly, CD69 was positively related to ENST00000528366 and negatively related to ENST00000509463. More proximal lncRNAs shared a greater number of mRNAs. For example, ENST00000417932 shared 235 mRNAs with nearby NR_038920, yet had just two mRNAs that it shared with ENST00000440436, and it shared no mRNAs with ENST00000528366.

Next, mRNAs with previously described associations with immune functions [36-53] were considered (Fig. 2a). Accordingly, 4 important lncRNAs and 47 related mRNAs from the 12 lncRNAs network (described above) were selected. In this second CNC network, there were 47 nodes representing mRNAs, as well as related genes (Fig. 2b). Of note, PTPN1 was found to be shared by ENST00000440492 and ENST00000528366, thereby implying that both of these IncRNAs exert their functions by regulating expression of PTPN1. ENST00000440492 was also found to be associated with CCR2 and CD36, two proteins which have been shown to play important roles in immune-related diseases. Therefore, ENST00000440492 may mediate its effects on ITP pathogenesis via these two genes. Similarly, CCRL2 and CD274 may be important for the function of ENST00000528366 in relation to ITP. Meanwhile, ENST00000552576 and NR_038920 were found to be associated with CCR7, CXCR1, PILRA, CD86, CD79B, and CCR7. A KEGG pathway analysis further revealed that related mRNAs for the 4 lncRNAs were enriched in pathway hsa04060: cytokine-cytokine receptor interaction - Homo sapiens (human) and hsa04062: chemokine signaling pathway - Homo sapiens (human) (see online suppl. material, Fig. S4a-b). Moreover, in the GO analysis, these mRNAs were closely associated with GO:0050896 (response to stimulus) and GO: 0009987 (cellular process) (see online suppl. material, Fig. S4c), which both belong to the biological process group and indicate possible immune functions.

\section{qRT-PCR}

To confirm the microarray results obtained, expression levels of 12 lncRNAs in CNC network and TCONS_00000918, TCONS_00003870 listed (see online suppl. material), in Table S1 were assayed by qRT-PCR in 30 $\mathrm{P} 1$ patients and $30 \mathrm{P} 2$ patients. Characteristics of these patients are summarized in Table 1. According to the P values, NR_038920, ENST00000528366,

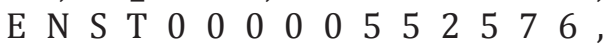
ENST00000440492 showed better examination efficiency in distinguishing

Table 2. Results of qRT-PCR for some of the vital lncRNAs and their fold changes. Abbreviations: P1: newly diagnosed ITP; P2: chronic ITP; N, normal. * If the IncRNAs were presented in different groups with different fold changes, then the average values would be calculated

\begin{tabular}{lcccc}
\hline Sequence Name & P1 vs N & $\begin{array}{c}\text { P-Value } \\
\text { P2 vs N }\end{array}$ & P2 vs P1 & $\begin{array}{c}\text { Average* } \\
\text { Fold Change }\end{array}$ \\
\hline ENST00000440492 & $4.915 \mathrm{E}-19$ & 0.376 & $6.985 \mathrm{E}-13$ & 3.187 \\
ENST00000509463 & 0.581 & 0.626 & 0.466 & 13.468 \\
uc010kun.2 & 0.00739 & 0.000717 & 0.186 & 12.296 \\
ENST00000436506 & 0.0402 & 0.00387 & 0.582 & 2.634 \\
ENST00000528366 & $1.623 \mathrm{E}-15$ & $5.097 \mathrm{E}-08$ & 0.000765 & 18.546 \\
ENST00000440436 & 0.0466 & 0.0401 & 0.678 & 9.855 \\
uc002ubt.1 & 0.447 & 0.828 & 0.416 & 2.493 \\
ENST00000417932 & 0.0220 & 0.0170 & 0.597 & 2.457 \\
NR_038920 & $2.781 \mathrm{E}-08$ & $3.636 \mathrm{E}-11$ & $2.655 \mathrm{E}-08$ & 8.943 \\
ENST00000412084 & 0.000187 & 0.0419 & 0.121 & 5.271 \\
ENST00000552576 & 0.000111 & 0.000261 & 0.231 & 3.503 \\
ENST00000521756 & 0.0337 & 0.0127 & 0.620 & 2.521 \\
TCONS_00000918 & 0.00815 & 0.00133 & 0.302 & 30.577 \\
TCONS_00003870 & 0.0106 & 0.00258 & 0.579 & 140.009 \\
\hline
\end{tabular}




\section{Cellular Physiology Cell Physiol Biochem 2018;48:618-632 \begin{tabular}{l|l} 
DOI: 10.1159/000491890 & $\begin{array}{l}\text { O } 2018 \text { The Author(s). Published by S. Karger AG, Basel } \\
\text { www.karger.com/cpb }\end{array}$
\end{tabular} \\ Li et al.: Abnormal Long Noncoding RNAs in Primary Immune Thrombocytopenia}

P1 from N, P2 from N, and P2 from P1 than other IncRNAs (Table 2). In detail, expression of NR_038920 significantly differed between the $\mathrm{P} 1$ and $\mathrm{N}$ groups, between the $\mathrm{P} 2$ and $\mathrm{N}$ groups, and between the P2 and P1 groups. ENST00000528366 also significantly differed between these three groups. In addition, ENST00000552576 distinguished the P1 samples from the $\mathrm{N}$ samples and the P2 samples from the $\mathrm{N}$ samples, while ENST00000440492 significantly differed between the P1 and $\mathrm{N}$ groups and between the $\mathrm{P} 2$ and $\mathrm{P} 1$ groups (Fig. 3a-d, P-values were shown in Table 2). AUCs of the ROC curves for the four lncRNAs ranged from 0.531 to 0.997, implying that these lncRNAs can distinguish different stages of ITP and the presence or absence of ITP, particularly NR_038920 (AUC: 0.857-0.958) and ENST00000528366 (AUC: 0.758-0.962) (Fig. 3e-h).

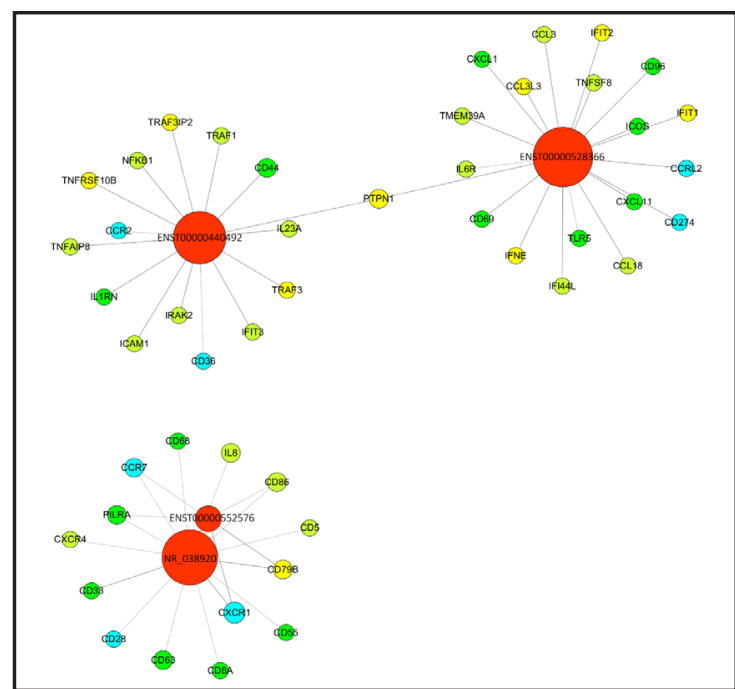

Fig. 3. Box plots (a-d) and ROC curves (e-h) for gene expression of ENST00000440492, ENST00000528366, NR_038920, and ENST00000552576. Blue, P1 vs N, Green, P2 vs N, Red, P2 vs P1, ns:not significant, ${ }^{*} \mathrm{P}<0.001,{ }^{* *} \mathrm{P}<0.0001$.

Furthermore, we also examined the gene expression of CCR7, CXCR1, CD274, CCRL2 by qRT-PCR as above, the results showed that the gene expressions of CXCR1 and CD274 were significantly different in P1 vs N, P2 vs N, P2 vs P1 groups. For CXCR1, the P-values were 0.000409, 1.11E-08, 0.000309, separately; for CD274, 0.00444, 3.696E-07, 0.0109, separately. CCR7 and CCRL2 were statistically different in P1 vs N, and P2 vs N groups. For CCR7, P-values were 0.00316, 2.529E-05, individually; for CCRL2, 0.00160, 3.86E-05, separately (see online suppl. material, Fig. S5).

\section{Discussion}

ITP is an autoimmune disorder that is characterized by pathologically produced lymphocytes, abnormally developed megakaryocytes, and/or biologically disordered platelets [5]. With the development of second generation sequence analysis (especially RNAseq), an increasing number of lncRNAs are being identified, as well as their roles in various types of diseases, including cancers (e.g., hepatocellular carcinoma, prostate cancer, etc.) and autoimmune diseases (e.g., SLE, SS, etc.) [54-56]. Previous studies have shown that lncRNAs potentially influence the functions of dendritic cells (DCs) and T lymphocytes, and also affect the differentiation of Th1/Th2 cells which play an important role in the development of ITP [57-59]. For example, targeting of STAT3 by lnc-DC involves the differentiation of DCs, and this in turn can induce the activation of an immune response [57]. In addition, linc-MAF-4 influences the differentiation of $\mathrm{CD}^{+} \mathrm{T}$ lymphocytes by targeting the chromatin modifiers, EZH2 and LSD1[60]. Considering the potential roles that lncRNAs may have in autoimmune disorders, they have received greater attention in recent years. As a result, specific roles for lncRNAs in autoimmune diseases such as SLE, RA, and SS have been elucidated [20-22].

In the present study, IncRNAs were profiled in three newly diagnosed ITP patients, in three chronic recurrent ITP patients, and in three healthy individuals by microarray (Fig. 1). The IncRNAs which exhibited the greatest fold-changes were NR_047631, ENST00000417071, and uc010idt.2 (see online suppl. material, Table S1a-b). We hypothesize that these lncRNAs may critically affect ITP pathology. To gain insight into the biological functions of these IncRNAs, bioinformatics were applied. As a result, ENST00000559553 was found to be related to "normal mucosa of esophagus-specific gene 1 protein". Previously, normal mucosa 
of esophagus-specific gene 1 protein was overexpressed in an esophageal squamous cell carcinoma cell line and cell motility was found to be affected [61].

In the GO analysis of down-regulated lncRNAs identified from a comparison of P1 versus $\mathrm{N}$ group data, three terms were predominant: "regulation of granulocyte macrophage colony-stimulating factor (GM-CSF) production", "coreceptor activity", and "T cell receptor complex" (see online suppl. material, Fig. S1d-f). These results suggest that differentially expressed lncRNAs may contribute to the pathology of ITP by influencing production of GMCSF, coreceptor activity, and/or T cell receptors, and these correlations are consistent with the results of previous studies which have characterized the pathogenesis of autoimmune diseases [62]. For example, in patients with multiple sclerosis (MS), an increase in GM-CSFexpressing B cells has been detected, and this increase could activate myeloid cells in a GMCSF-dependent manner [63]. In relation to B cells, CD22 is a co-receptor of these cells and is reported to control the B cell response to antigens. Thus, dysfunction of CD22 could lead to the development of autoimmune diseases such as SLE. Correspondingly, epratuzumab, a monoclonal antibody recognizing CD22, is a potential treatment for SLE[64]. T cells and their receptors have also been characterized as critical immune factors in immune-related diseases, with T cell receptors (TCRs) being able to recognize restricted antigenic peptide fragments and mediate signaling via transduction pathways which are critical for T cell activation [65]. Regarding the latter, decreased tyrosine phosphorylation of the TCR zetachain has been linked to defective TCR signaling that may underlie the hyporesponsiveness of synovial T cells in RA[66].

Metabolism-associated GO terms were also identified in the present study. These included: "long-chain fatty acid binding", "oxygen transporter activity", "oxygen transport", and inflammation-related terms such as "response to bacterium" and "fever generation". It is well established that ITP represents a complex disease that is accompanied by an inflammatory reaction mediated by a variety of immune cytokines including IL-17, IFN- $\gamma$, and TNF- $\alpha$, among others. It has also been observed that the metabolism of these cytokines can change over the course of this disease, including their oxidant and antioxidant states, and these changes can potentially influence the development of ITP[33, 67-69]. It is possible that differentially expressed lncRNAs exert their functions by influencing inflammatory or metabolism processes, and these effects could influence the development of ITP. In the pathway analysis conducted in the present study, the "TNF signaling pathway - Homo sapiens (human)" was markedly enriched in a comparison of the down-regulated lncRNAs between the P1 and N groups (see online suppl. material, Fig. S2a). Previous studies have shown that TNFR1 and TNFR2 are two important receptors that mediate signaling downstream of TNF activation and binding [70]. In general, signaling via TNF-TNFR1 involves the MAPK and NF$\kappa \beta$ pathways. In contrast, signaling via TNF-TNFR2 is limited to $C D 4^{+} \mathrm{T}$ cells, $\mathrm{CD} 8^{+} \mathrm{T}$ cells, and endothelial cells, and signaling via NF- $\kappa \beta$ can be stimulated as well [70-74]. Between the P 2 and $\mathrm{N}$ group data, the most enriched pathway that was identified was the, "NF-kappa B signaling pathway - Homo sapiens (human)" (see online suppl. material, Fig. S2g); and between the P2 and P1 group data, the "Rheumatoid arthritis - Homo sapiens (human)" pathway was identified (see online suppl. material, Fig. S2b-c). A role for the NF- $\kappa \beta$ signaling pathway in maintaining immune tolerance in the body has previously been demonstrated, including its roles in central and peripheral tolerance which include an inhibition of regulatory $\mathrm{T}$ cells $[75,76]$. Thus, NF- $\kappa \beta$ signaling is an important mediator in regulating chronic inflammatory diseases and autoimmune diseases [77]. In brain tissues affected by MS, NF- $\kappa \beta$ has also been shown to localize to astrocytes and infiltrating macrophages in or near lesions in the central nervous system $[77,78]$. Furthermore, genetic studies have shown that abnormal levels of NF- $\kappa \beta$-related genes may be related to MS relapses $[79,80]$. Regarding the RA pathway that was identified in a comparison of the P2 and P1 groups, enrichment of this pathway may be due to similarities in the underlying mechanisms of these two diseases, which include the involvement of $\mathrm{CD} 4^{+} \mathrm{T}$ cells, the NF- $\kappa \beta$ signaling pathway, and aberrant expression of cytokines such as IFN- $\gamma$. Moreover, clinically, patients with RA are often complicated by 
immune thrombocytopenic purpura, thereby further supporting the relationship between these two diseases [81-84].

For the CNC analysis, we initially selected 12 lncRNAs. Then, four of these 12 lncRNAs were selected for further analysis (Fig. 2, a and b). As a result, NR_038920 appear to share related genes with ENST00000552576, such as CCR7 and CXCR1 (Fig. 2b). CCR7 has been shown to play an important role in adaptive immune activities as part of a CCR7-CCL19/ CCL21 signaling axis. This axis has been shown to affect T lymphocyte function, DCs, and $\mathrm{T}$ cell priming or adaptive immunity in lymph nodes $[85,86]$. Furthermore, CCR7 has also been shown to promote $\mathrm{T}$ cell development and lymphorganogenesis, two processes which are significant in the progression of autoimmune diseases $[85,86]$. Thus, inappropriate regulation of the CCR7-CCL19/CCL21 axis may lead to immune disorders, including the development of autoimmune diseases [85]. Regarding CXCR1, it has always been found to function in combination with CXCR2. The CXCR1/2 complex has been detected on neutrophils, macrophages, and lymphocytes, and these cell types are critical in inflammatory processes and autoimmune diseases $[50,87,88]$. Inhibition of CXCR1/ 2 has been shown to prevent islet damage due to immune disorders, and this inhibition also promotes autoimmune throditis [50]. Alternatively, the CXCR1/CXCL8 axis has been associated with the accumulation of NK cells in the liver of patients with primary biliary disease, thereby contributing to the pathological development of this disease [89]. ENST00000528366 is shown to be related with CD274 and CCRL2. CD274, also known as ligand for programmed cell death 1 (PD-L1), is expressed on the surface of lymphocytes, macrophages or the dendritic cells [48]. After interacting with PD-1, it can regulate the proliferation or the immune-tolerance of T cells, it is emphasized in the T cell-mediated autoimmune diseases such as SLE, MS, et al $[90,91]$. In patients with active SLE, PD-L1 is found to be overexpressed in monocytes and negatively related with the level of TGF- $\beta$, while interestingly when patients are in the recovery stage, PD-L1 is showed to be positively related to TNF- $\alpha$, implying that PD-L1 may involve in the pathogenesis of SLE by influencing the expression of TGF- $\beta$ or TNF- $\alpha$ [90]. Chemokine (CC motif) receptor-like 2 (CCRL2) is a 7-transmembrane protein related to the family of the typical chemokine receptors that participate in the inflammation process, for example, in the murine models of experimental autoimmune encephalitis, those short of CCRL2 develop exacerbated nonresolving disease and recurrent inflammatory reactions, suggesting that it may take part in the control of multiple sclerosis [46]. Based on the roles CCRL2 and CD274 played in the process of autoimmune diseases, in ITP ENST00000528366 may also involve in its pathogenesis through the pathways as described above.

According to the literature regarding ITP, ENST00000440492, ENST00000528366, NR_038920, and ENST00000552576 may act through similar pathways. For example, when the pathways or GO terms associated with the mRNAs in the CNC network were searched to reveal their related lncRNAs' functions, hsa04060: cytokine-cytokine receptor interaction - Homo sapiens (human) (see online suppl. material, Fig. S4b) and hsa04062: chemokine signaling pathway - Homo sapiens (human) (see online suppl. material, Fig. S4a) pathways were identified. The GO results further suggest that these lncRNAs may mediate functions associated with stimulus response (G0:0050896) and cellular processes (G0: 0009987) (see online suppl. material, Fig. S4c).

To further verify the microarray results of the present study, qRT-PCR was performed to detect ENST00000440492, ENST00000528366, NR_038920, and ENST00000552576 in 30 patients with newly diagnosed ITP (P1) and 30 patients with chronic recurrent ITP (P2). These results (Fig. 3a-d), in combination with the ROC curves data (Fig. 3e-h), confirm that these four IncRNAs can efficiently distinguish different stages of ITP, especially NR_038920 and ENST00000528366 which can distinguish P1, P2 from N and P1 from P2 (ENST00000440492 cannot distinguish P2 from N, and ENST00000552576 cannot distinguish P2 from P1). Consequently, these lncRNAs may represent potential targets for monitoring, diagnosing, and/or treating ITP.

To our knowledge, this is the first microarray-based study to investigate lncRNAs in ITP. The identification of differentially expressed lncRNAs in this study provides support

\section{KARGER}




\section{Cellular Physiology Cell Physiol Biochem 2018;48:618-632 \begin{tabular}{l|l} 
DOI: 10.1159/000491890 & Ond Biochemistry \\
Published online: July 18, 2018 & $\begin{array}{l}\text { 2018 The Author(s). Published by S. Karger AG, Basel } \\
\text { www.karger.com/cpb }\end{array}$
\end{tabular}}

Li et al.: Abnormal Long Noncoding RNAs in Primary Immune Thrombocytopenia

for further analyses regarding their functions in this disease process. As described above, lncRNAs may exert their functions by influencing other molecules or via actions through certain pathways. Accordingly, the latter has been demonstrated for a subset of IncRNAs in relation to the development of certain autoimmune diseases. Thus, it appears that lncRNAs have the capacity to facilitate monitoring of ITP progression and to serve as targets for the treatment of this disease, and further studies of lncRNAs are warranted.

\section{Acknowledgements}

This research was supported by grants from the National 973 Foundation (2013CB531606), the National Science Foundation of China (81701608, 81671556, 81601406, 81501397, 31500721, 81501398, 81471605, 81401358, 81302579, 81273282 and 81202353), Shanghai Shenkang (SHDC22014014), Shanghai Educational Science (D14017), Army Scientific Research (BWS14J023, 15ZD009,15XD007), China Postdoctoral Science Foundation (2017M623440) and MJD Founding (MJR20150019).

\section{Disclosure Statement}

The authors have no competing interests to declare.

\section{References}

-1 Neunert C, Lim W, Crowther M, Cohen A, Solberg L, Jr., Crowther MA: The American Society of Hematology 2011 evidence-based practice guideline for immune thrombocytopenia. Blood 2011;117:4190-4207.

2 Schipperus M, Fijnheer R: New therapeutic options for immune thrombocytopenia. Neth J Med 2011;69:480-485.

3 Ji X, Zhang L, Peng J, Hou M: T cell immune abnormalities in immune thrombocytopenia. J Hematol Oncol 2014;7:72.

4 Kuwana M, Kaburaki J, Ikeda Y: Autoreactive T cells to platelet GPIIb-IIIa in immune thrombocytopenic purpura. Role in production of anti-platelet autoantibody. J Clin Invest 1998;102:1393-1402.

5 Gernsheimer T: Chronic idiopathic thrombocytopenic purpura: mechanisms of pathogenesis. Oncologist 2009;14:12-21.

6 Zhou Z, Li X, Li J, Su C, Zhuang L, Luo S, Zhang L: Direct B-cell stimulation by peripheral blood monocytederived dendritic cells in idiopathic thrombocytopenic purpura patients. J Clin Immunol 2010;30:814-822.

7 Jernas M, Nookaew I, Wadenvik H, Olsson B: MicroRNA regulate immunological pathways in T-cells in immune thrombocytopenia (ITP). Blood 2013;121:2095-2098.

-8 Hrdlickova B, Kumar V, Kanduri K, Zhernakova DV, Tripathi S, Karjalainen J, Lund RJ, Li Y, Ullah U, Modderman R, Abdulahad W, Lahdesmaki H, Franke L, Lahesmaa R, Wijmenga C, Withoff S: Expression profiles of long non-coding RNAs located in autoimmune disease-associated regions reveal immune celltype specificity. Genome Med 2014;6:88.

-9 Bodenreider 0, Burgun A: A framework for comparing phenotype annotations of orthologous genes. Stud Health Technol Inform 2010;160:1309-1313.

10 Harper M, Gronenberg L, Liao J, Lee C: Comprehensive detection of genes causing a phenotype using phenotype sequencing and pathway analysis. PLoS One 2014;9:e88072.

11 Luo J, Liang S: Prioritization of potential candidate disease genes by topological similarity of proteinprotein interaction network and phenotype data. J Biomed Inform 2015;53:229-236.

12 Gernapudi R, Wolfson B, Zhang Y, Yao Y, Yang P, Asahara H, Zhou Q: MicroRNA 140 Promotes Expression of Long Noncoding RNA NEAT1 in Adipogenesis. Mol Cell Biol 2016;36:30-38.

13 Shi Q Yang X: Circulating MicroRNA and Long Noncoding RNA as Biomarkers of Cardiovascular Diseases. J Cell Physiol 2016;231:751-755. 


\section{Cellular Physiology Cell Physiol Biochem 2018;48:618-632

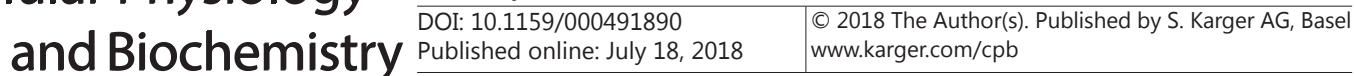

Li et al.: Abnormal Long Noncoding RNAs in Primary Immune Thrombocytopenia

14 Sui W, Lin H, Peng W, Huang Y, Chen J, Zhang Y, Dai Y: Molecular dysfunctions in acute rejection after renal transplantation revealed by integrated analysis of transcription factor, microRNA and long noncoding RNA. Genomics 2013;102:310-322.

15 Song X, Cao G, Jing L, Lin S, Wang X, Zhang J, Wang M, Liu W, Lv C: Analysing the relationship between lncRNA and protein-coding gene and the role of IncRNA as ceRNA in pulmonary fibrosis. J Cell Mol Med 2014;18:991-1003.

16 Kazemzadeh M, Safaralizadeh R, Orang AV: LncRNAs: emerging players in gene regulation and disease pathogenesis. J Genet 2015;94:771-784.

17 Li X, Wu Z, Fu X, Han W: IncRNAs: insights into their function and mechanics in underlying disorders. Mutat Res Rev Mutat Res 2014;762:1-21.

18 Wu Z, Liu X, Liu L, Deng H, Zhang J, Xu Q, Cen B, Ji A: Regulation of IncRNA expression. Cell Mol Biol Lett 2014;19:561-575.

19 Sigdel KR, Cheng A, Wang Y, Duan L, Zhang Y: The Emerging Functions of Long Noncoding RNA in Immune Cells: Autoimmune Diseases. J Immunol Res 2015;2015:848790.

20 Haywood ME, Rose SJ, Horswell S, Lees MJ, Fu G, Walport MJ, Morley BJ: Overlapping BXSB congenic intervals, in combination with microarray gene expression, reveal novel lupus candidate genes. Genes Immun 2006;7:250-263.

21 Wu GC, Li J, Leng RX, Li XP, Li XM, Wang DG, Pan HF, Ye DQ: Identification of long non-coding RNAs GAS5, linc0597 and lnc-DC in plasma as novel biomarkers for systemic lupus erythematosus. Oncotarget 2017;8:23650-23663.

22 Song J, Kim D, Han J, Kim Y, Lee M, Jin EJ: PBMC and exosome-derived Hotair is a critical regulator and potent marker for rheumatoid arthritis. Clin Exp Med 2015;15:121-126.

23 Zhou JZ, Li JJ, Hua DJ, Huang SC, Sun QQ Huang H, Xin XF, Cen H: A study on associations of singlenucleotide polymorphisms within H19 and HOX transcript antisense RNA (HOTAIR) with genetic susceptibility to rheumatoid arthritis in a Chinese population. Inflamm Res 2017;66:515-521.

24 Wang J, Peng H, Tian J, Ma J, Tang X, Rui K, Tian X, Wang Y, Chen J, Lu L, Xu H, Wang S: Upregulation of long noncoding RNA TMEVPG1 enhances T helper type 1 cell response in patients with Sjogren syndrome. Immunol Res 2016;64:489-496.

25 Li H, Hao Y, Zhang D, Fu R, Liu W, Zhang X, Xue F, Yang R: Aberrant expression of long noncoding RNA TMEVPG1 in patients with primary immune thrombocytopenia. Autoimmunity 2016;49:496-502.

-26 Rodeghiero F, Stasi R, Gernsheimer T, Michel M, Provan D, Arnold DM, Bussel JB, Cines DB, Chong BH, Cooper N, Godeau B, Lechner K, Mazzucconi MG, McMillan R, Sanz MA, Imbach P, Blanchette V, Kuhne T, Ruggeri M, George JN: Standardization of terminology, definitions and outcome criteria in immune thrombocytopenic purpura of adults and children: report from an international working group. Blood 2009;113:2386-2393.

27 Cuker A: ITP and TTP: interpreting evidence in light of patient values. Blood 2015;125:1514-1515.

28 Culic S, Salamunic I, Konjevoda P, Dajak S, Pavelic J: Immune thrombocytopenia: serum cytokine levels in children and adults. Med Sci Monit 2013;19:797-801.

29 Del Vecchio GC, Giordano P, Tesse R, Piacente L, Altomare M, De Mattia D: Clinical significance of serum cytokine levels and thrombopoietic markers in childhood idiopathic thrombocytopenic purpura. Blood Transfus 2012;10:194-199.

-30 Feng X, Scheinberg P, Samsel L, Rios O, Chen J, McCoy JP, Jr., Ghanima W, Bussel JB, Young NS: Decreased plasma cytokines are associated with low platelet counts in aplastic anemia and immune thrombocytopenic purpura. J Thromb Haemost 2012;10:1616-1623.

31 Jernas M, Hou Y, Stromberg Celind F, Shao L, Nookaew I, Wang Q Ju X, Mellgren K, Wadenvik H, Hou M, Olsson B: Differences in gene expression and cytokine levels between newly diagnosed and chronic pediatric ITP. Blood 2013;122:1789-1792.

32 Jernas M, Hou Y, Stromberg Celind F, Shao L, Wang Q Ju X, Mellgren K, Wadenvik H, Hou M, Olsson B: Altered cytokine levels in pediatric ITP. Platelets 2015;26:589-592.

-33 Leontyev D, Neschadim A, Branch DR: Cytokine profiles in mouse models of experimental immune thrombocytopenia reveal a lack of inflammation and differences in response to intravenous immunoglobulin depending on the mouse strain. Transfusion 2014;54:2871-2879.

34 Pourcelot E, Trocme C, Mondet J, Bailly S, Toussaint B, Mossuz P: Cytokine profiles in polycythemia vera and essential thrombocythemia patients: clinical implications. Exp Hematol 2014;42:360-368. 


\section{Cellular Physiology Cell Physiol Biochem 2018;48:618-632 \begin{tabular}{l|l|l} 
and Biochemistry & Dublishe.1159/000491890 & $\begin{array}{l}\text { C } 2018 \text { The Author(s). Published by S. Karger AG, Basel } \\
\text { www.karger.com/cpb }\end{array}$
\end{tabular}

35 Talaat RM, Elmaghraby AM, Barakat SS, El-Shahat M: Alterations in immune cell subsets and their cytokine secretion profile in childhood idiopathic thrombocytopenic purpura (ITP). Clin Exp Immunol 2014;176:291-300.

-36 Antonelli A, Ferrari SM, Ruffilli I, Fallahi P: Cytokines and HCV-related autoimmune disorders. Immunol Res 2014;60:311-319.

-37 Holdsworth SR, Gan PY: Cytokines: Names and Numbers You Should Care About. Clin J Am Soc Nephrol 2015;10:2243-2254.

38 Storan ER, O'Gorman SM, McDonald ID, Steinhoff M: Role of cytokines and chemokines in itch. Handb Exp Pharmacol 2015;226:163-176.

39 Venkatesha SH, Dudics S, Acharya B, Moudgil KD: Cytokine-modulating strategies and newer cytokine targets for arthritis therapy. Int J Mol Sci 2014;16:887-906.

40 Postal M, Appenzeller S: The importance of cytokines and autoantibodies in depression. Autoimmun Rev 2015;14:30-35.

41 Wang K, Grivennikov SI, Karin M: Implications of anti-cytokine therapy in colorectal cancer and autoimmune diseases. Ann Rheum Dis 2013;72 Suppl 2:ii100-103.

42 Yang CA, Chiang BL: Inflammasomes and human autoimmunity: A comprehensive review. J Autoimmun 2015;61:1-8.

43 Gu D, Chen Z, Zhao H, Du W, Xue F, Ge J, Sui T, Wu H, Liu B, Lu S, Zhang L, Yang R: Th1 (CXCL10) and Th2 (CCL2) chemokine expression in patients with immune thrombocytopenia. Hum Immunol 2010;71:586591.

-44 Schultz DR, Arnold PI, Jy W, Valant PA, Gruber J, Ahn YS, Mao FW, Mao WW, Horstman LL: Anti-CD36 autoantibodies in thrombotic thrombocytopenic purpura and other thrombotic disorders: identification of an $85 \mathrm{kD}$ form of CD36 as a target antigen. Br J Haematol 1998;103:849-857.

45 Xu X, Ye X, Xia W, Liu J, Ding H, Deng J, Chen Y, Shao Y, Wang J, Fu Y, Santoso S: Studies on CD36 deficiency in South China: Two cases demonstrating the clinical impact of anti-CD36 antibodies. Thromb Haemost 2013;110:1199-1206.

46 Mazzon C, Zanotti L, Wang L, Del Prete A, Fontana E, Salvi V, Poliani PL, Sozzani S: CCRL2 regulates M1/M2 polarization during EAE recovery phase. J Leukoc Biol 2016;99:1027-1033.

47 Salvi V, Sozio F, Sozzani S, Del Prete A: Role of Atypical Chemokine Receptors in Microglial Activation and Polarization. Front Aging Neurosci 2017;9:148.

48 Dai S, Jia R, Zhang X, Fang Q, Huang L: The PD-1/PD-Ls pathway and autoimmune diseases. Cell Immunol 2014;290:72-79.

49 Wichner K, Fischer A, Winter S, Tetzlaff S, Heimesaat MM, Bereswill S, Rehm A, Lipp M, Hopken UE: Transition from an autoimmune-prone state to fatal autoimmune disease in CCR7 and RORgammat doubledeficient mice is dependent on gut microbiota. J Autoimmun 2013;47:58-72.

50 Citro A, Cantarelli E, Piemonti L: The CXCR1/2 Pathway: Involvement in Diabetes Pathophysiology and Potential Target for T1D Interventions. Curr Diab Rep 2015;15:68.

-51 Citro A, Valle A, Cantarelli E, Mercalli A, Pellegrini S, Liberati D, Daffonchio L, Kastsiuchenka O, Ruffini PA, Battaglia M, Allegretti M, Piemonti L: CXCR1/2 inhibition blocks and reverses type 1 diabetes in mice. Diabetes 2015;64:1329-1340.

-52 Badawi AH, Kiptoo P, Siahaan TJ: Immune Tolerance Induction against Experimental Autoimmune Encephalomyelitis (EAE) Using A New PLP-B7AP Conjugate that Simultaneously Targets B7/CD28 Costimulatory Signal and TCR/MHC-II Signal. J Mult Scler (Foster City) 2015;2:

53 Dumitriu IE: The life (and death) of CD4+ CD28(null) T cells in inflammatory diseases. Immunology 2015;146:185-193.

54 Wu GC, Pan HF, Leng RX, Wang DG, Li XP, Li XM, Ye DQ: Emerging role of long noncoding RNAs in autoimmune diseases. Autoimmun Rev 2015;14:798-805.

55 Li C, Chen J, Zhang K, Feng B, Wang R, Chen L: Progress and Prospects of Long Noncoding RNAs (lncRNAs) in Hepatocellular Carcinoma. Cell Physiol Biochem 2015;36:423-434.

56 Luo G, Wang M, Wu X, Tao D, Xiao X, Wang L, Min F, Zeng F, Jiang G: Long Non-Coding RNA MEG3 Inhibits Cell Proliferation and Induces Apoptosis in Prostate Cancer. Cell Physiol Biochem 2015;37:2209-2220.

57 Wang P, Xue Y, Han Y, Lin L, Wu C, Xu S, Jiang Z, Xu J, Liu Q, Cao X: The STAT3-binding long noncoding RNA lnc-DC controls human dendritic cell differentiation. Science 2014;344:310-313. 


\section{Cellular Physiology Cell Physiol Biochem 2018;48:618-632 \begin{tabular}{l|l|l} 
and Biochemistry & $\begin{array}{l}\text { DOI: 10.1159/000491890 } \\
\text { Published } 2018\end{array}$ & $\begin{array}{l}\text { @ } 2018 \text { The Author(s). Published by S. Karger AG, Basel } \\
\text { www.karger.com/cpb }\end{array}$
\end{tabular}}

Li et al.: Abnormal Long Noncoding RNAs in Primary Immune Thrombocytopenia

58 Hu G, Tang Q, Sharma S, Yu F, Escobar TM, Muljo SA, Zhu J, Zhao K: Expression and regulation of intergenic long noncoding RNAs during T cell development and differentiation. Nat Immunol 2013;14:1190-1198.

59 Spurlock CF, 3rd, Tossberg JT, Guo Y, Collier SP, Crooke PS, 3rd, Aune TM: Expression and functions of long noncoding RNAs during human T helper cell differentiation. Nat Commun 2015;6:6932.

60 Zhang F, Liu G, Wei C, Gao C, Hao J: Linc-MAF-4 regulates Th1/Th2 differentiation and is associated with the pathogenesis of multiple sclerosis by targeting MAF. FASEB J 2017;31:519-525.

61 Arai M, Imazeki F, Sakai Y, Mikata R, Tada M, Seki N, Shimada H, Ochiai T, Yokosuka O: Analysis of the methylation status of genes up-regulated by the demethylating agent, 5-aza-2'-deoxycytidine, in esophageal squamous cell carcinoma. Oncol Rep 2008;20:405-412.

62 Wang L, Wang FS, Gershwin ME: Human autoimmune diseases: a comprehensive update. J Intern Med 2015;278:369-395.

63 Li R, Rezk A, Miyazaki Y, Hilgenberg E, Touil H, Shen P, Moore CS, Michel L, Althekair F, Rajasekharan S, Gommerman JL, Prat A, Fillatreau S, Bar-Or A: Proinflammatory GM-CSF-producing B cells in multiple sclerosis and B cell depletion therapy. Sci Transl Med 2015;7:310ra166.

64 Dorner T, Shock A, Smith KG: CD22 and autoimmune disease. Int Rev Immunol 2012;31:363-378.

65 Sakaguchi S, Benham H, Cope AP, Thomas R: T-cell receptor signaling and the pathogenesis of autoimmune arthritis: insights from mouse and man. Immunol Cell Biol 2012;90:277-287.

66 Maurice MM, Lankester AC, Bezemer AC, Geertsma MF, Tak PP, Breedveld FC, van Lier RA, Verweij CL: Defective TCR-mediated signaling in synovial T cells in rheumatoid arthritis. J Immunol 1997;159:29732978.

67 Jin CQ Dong HX, Cheng PP, Zhou JW, Zheng BY, Liu F: Antioxidant status and oxidative stress in patients with chronic ITP. Scand J Immunol 2013;77:482-487.

68 Li HY, Zhang DL, Zhang X, Liu XF, Xue F, Yang RC: Interleukin-7 is decreased and maybe plays a proinflammatory function in primary immune thrombocytopenia. Platelets 2015;26:243-249.

-69 McKenzie CG, Guo L, Freedman J, Semple JW: Cellular immune dysfunction in immune thrombocytopenia (ITP). Br J Haematol 2013;163:10-23.

70 Rossol M, Meusch U, Pierer M, Kaltenhauser S, Hantzschel H, Hauschildt S, Wagner U: Interaction between transmembrane TNF and TNFR1/2 mediates the activation of monocytes by contact with T cells. J Immunol 2007;179:4239-4248.

71 Deckert-Schluter M, Bluethmann H, Rang A, Hof H, Schluter D: Crucial role of TNF receptor type 1 (p55), but not of TNF receptor type 2 (p75), in murine toxoplasmosis. J Immunol 1998;160:3427-3436.

72 Eugster HP, Frei K, Bachmann R, Bluethmann H, Lassmann H, Fontana A: Severity of symptoms and demyelination in MOG-induced EAE depends on TNFR1 Eur J Immunol 1999;29:626-632.

73 Funk JO, Walczak H, Voigtlander C, Berchtold S, Baumeister T, Rauch P, Rossner S, Steinkasserer A, Schuler G, Lutz MB: Cutting edge: resistance to apoptosis and continuous proliferation of dendritic cells deficient for TNF receptor-1 J Immunol 2000;165:4792-4796.

74 Gane JM, Stockley RA, Sapey E: TNF-alpha Autocrine Feedback Loops in Human Monocytes: The Pro- and Anti-Inflammatory Roles of the TNF-alpha Receptors Support the Concept of Selective TNFR1 Blockade In Vivo. J Immunol Res 2016;2016:1079851.

-75 Oh H, Ghosh S: NF-kappaB: roles and regulation in different CD4(+) T-cell subsets. Immunol Rev 2013;252:41-51.

-76 Ruan Q Chen YH: Nuclear factor-kappaB in immunity and inflammation: the Treg and Th17 connection. Adv Exp Med Biol 2012;946:207-221.

77 Sun SC, Chang JH, Jin J: Regulation of nuclear factor-kappaB in autoimmunity. Trends Immunol 2013;34:282-289.

78 Bonetti B, Stegagno C, Cannella B, Rizzuto N, Moretto G, Raine CS: Activation of NF-kappaB and c-jun transcription factors in multiple sclerosis lesions. Implications for oligodendrocyte pathology. Am J Pathol 1999;155:1433-1438.

79 Lindsey JW, Agarwal SK, Tan FK: Gene expression changes in multiple sclerosis relapse suggest activation of T and non-T cells. Mol Med 2011;17:95-102.

80 Satoh J, Misawa T, Tabunoki H, Yamamura T: Molecular network analysis of T-cell transcriptome suggests aberrant regulation of gene expression by NF-kappaB as a biomarker for relapse of multiple sclerosis. Dis Markers 2008;25:27-35. 


\section{Cellular Physiology Cell Physiol Biochem 2018;48:618-632 \begin{tabular}{l|l} 
DOI: 10.1159/000491890 & $\begin{array}{l}\text { O 2018 The Author(s). Published by S. Karger AG, Basel } \\
\text { www.karger.com/cpb }\end{array}$
\end{tabular} \\ Li et al.: Abnormal Long Noncoding RNAs in Primary Immune Thrombocytopenia}

81 Gal I, Toth L, Szegedi L, Kiss GG: Gastric bleeding in a patient with rheumatoid arthritis complicated by immune thrombocytopenic purpura. Joint Bone Spine 2008;75:350-352.

82 Horino T, Sasaoka A, Takao T, Taguchi T, Maruyama H, Ito H, Takemoto S, Taguchi H, Hashimoto K: Immune thrombocytopenic purpura associated with rheumatoid arthritis: case report. Clin Rheumatol 2005;24:641-644.

83 Komoglu S, Silte D, Sertbas M, Sertbas Y, Ozdemir A: Methorexate therapy in a patient with rheumatoid arthritis complicated by idiopathic thrombocytopenic purpura. Eur J Rheumatol 2015;2:39-40.

84 Glant TT, Mikecz K, Rauch TA: Epigenetics in the pathogenesis of rheumatoid arthritis. BMC Med 2014;12:35.

-85 Hauser MA, Legler DF: Common and biased signaling pathways of the chemokine receptor CCR7 elicited by its ligands CCL19 and CCL21 in leukocytes. J Leukoc Biol 2016;99:869-882.

86 Comerford I, Harata-Lee Y, Bunting MD, Gregor C, Kara EE, McColl SR: A myriad of functions and complex regulation of the CCR7/CCL19/CCL21 chemokine axis in the adaptive immune system. Cytokine Growth Factor Rev 2013;24:269-283.

87 Diana J, Lehuen A: Macrophages and beta-cells are responsible for CXCR2-mediated neutrophil infiltration of the pancreas during autoimmune diabetes. EMBO Mol Med 2014;6:1090-1104.

88 Kerstetter AE, Padovani-Claudio DA, Bai L, Miller RH: Inhibition of CXCR2 signaling promotes recovery in models of multiple sclerosis. Exp Neurol 2009;220:44-56.

89 Maghazachi AA: Role of chemokines in the biology of natural killer cells. Curr Top Microbiol Immunol 2010;341:37-58.

-90 Ou JN, Wiedeman AE, Stevens AM: TNF-alpha and TGF-beta counter-regulate PD-L1 expression on monocytes in systemic lupus erythematosus. Sci Rep 2012;2:295.

$\$ 91$ Pittet CL, Newcombe J, Prat A, Arbour N: Human brain endothelial cells endeavor to immunoregulate CD8 T cells via PD-1 ligand expression in multiple sclerosis. J Neuroinflammation 2011;8:155. 